\title{
An investigation of semantic memory in individuals
}

\author{
VERONIKA COLTHEART \\ City of London Polytechnic, London E1 7NT, England \\ and \\ J. St. B. T. EVANS \\ Plymouth Polytechnic, Plymouth PL4 8AA, England
}

\begin{abstract}
This paper reports three experiments which examined individual differences in the semantic domain of bird names. In Experiment 1 each subject emitted his own list of 20 bird names and then scaled them using a rating scale version of the repertory grid test. This test requires that the subject generate a set of bipolar descriptive scales for the purposes of the scaling. Principal components analysis of the resulting data matrices were used to construct a semantic space for each of the subjects. Interpretation of the first three components for each subject suggested that most discriminate water and land birds; predatoriness was also a commonly found dimension. In Experiment 2 each subject classified each of the bird names s/he had listed in terms of the bipolar scales which arose during the scaling. As predicted, judgment reaction time (RT) was a U-shaped function of the location of the bird name on the bipolar scale. In Experiment 3 categorization of bird names was faster when a semantically close bird name was used as a prime than when a semantically distant bird name was the prime. These results demonstrate the practicability of an individual-differences approach to the study of semantic memory and show that individual semantic spaces can be used to predict RT performance in semantic memory tasks.
\end{abstract}

The structure of semantic memory has been investigated by Collins and Quillian (1969). They proposed that semantic memory is hierarchically organized, so that, for example, the semantic space referring to living creatures resembles a biological taxonomy. They further proposed that the structure of semantic memory directly determines the speed with which certain types of linguistic tasks (such as categorization and sentence verification) could be performed and presented evidence that supported their model. In their research, sentences were constructed with the aid of dictionary definitions and by the use of Roget's Thesaurus.

Subsequent studies of categorization and sentence verification revealed a variety of theoretical and empirical difficulties for the Collins-Quillian (1969) approach to semantic memory. For example, Wilkins (1971) considered the possibility that categorization reaction time (RT) might be related to frequency of usage in English. He then proceeded to manipulate "conjoint frequency," the frequency with which an instance occurs in response to a category name. Conjoint frequency was assessed by reference to category norms, and was found to be negatively correlated with categorization RT. Loftus (1973) decomposed conjoint frequency into

We would like to acknowledge with thanks the assistance of Neil Hyland, who collected the data and assisted in the analysis of results. We would also like to thank Max Coltheart and Denise Hale for helpful comments on a draft of this paper. "category dominance" and "instance dominance" and demonstrated that both of these variables can play a role in the determination of categorization RTs. Conrad (1972) obtained normative data on the frequency with which certain properties are used to describe the instance and category names used in semantic memory experiments. She found that property frequency was a good predictor of sentence verification times. Consequently, an adequate model of semantic memory must account for conjoint frequency effects, and subsequent models have attempted to do so (Collins \& Loftus, 1975; Smith, Shoben, \& Rips, 1974). However, these attempts to encompass the effects of actual English usage in models of semantic memory may be insufficient.

A comparison of category norms and word association norms obtained from different subgroups of the speakers of English shows that large systematic differences exist between groups of speakers of the same language. Category norm comparisons show that differences exist between undergraduates cross-nationally-for instance, between Scottish, Irish, and American undergraduates (Brown, 1978)-and word association norms show differences between different subgroups within a single national group (Cramer, 1968; Postman \& Keppel, 1970). It is possible, furthermore, that differences from person to person exist in the structure of semantic memory. It is clear that individuals are likely to differ in both their knowledge of and their interest in the categories used to study semantic memory. An example 
of this is provided by Collins and Quillian (1970), who observed that at least one of their subjects interpreted the meaning of the term "animal" as that of "mammal." It seemed possible that, because people differ considerably in their educational backgrounds and their leisure interests, and of course have been exposed to widely differing environments, their semantic structures might differ considerably. Thus, it seems possible that semantic spaces are to an important degree unique for individuals. These unique structures must be modifiable by experience, of course, since the acquisition of new information must at times radically alter the content and configuration of the existing structure. It should, however, be stressed that much of any person's knowledge of the world and of language is shared with other persons; if not, of course, communication would not be possible. Consequently, we would expect that both a zoologist and a student of English literature would appropriately process and respond to the sentence "The nightingale flew away." However, the representation of "nightingale" in semantic memory might differ considerably for the student of Keats who has encountered the term only in poetry and for the zoologist who watches birds as a hobby. Furthermore, the word "nightingale" might most effectively prime a rather different set of words for these subjects in a lexical decision experiment, although for both it may prime "song."

This paper explores the possibility that differences exist between people in the structure of semantic space. In order to study the structure of semantic memory in individuals, an idiographic technique, Kelly's repertory grid technique (Kelly, 1955), was used. This allows one to discover whether there are in fact substantial differences in the structure of semantic space from person to person. The technique was devised by Kelly in connection with his theory of personal constructs. He emphasized the need to study personality within individuals, and presented his idiographic grid methodology as a radical alternative to conventional multivariate methods. Subsequent developments have both refined the repertory grid methodology and detached it from any necessary theoretical commitment to Kelly's personality theory (cf. Slater, 1976, 1977). It is now used as a powerful idiographic scaling technique in a variety of settings, including clinical, educational, and market research. For a recent discussion of repertory grid methodology and its applications, the reader is referred to Adams-Webber (1979).

Repertory grids are idiographic in two respects. First, the subject generates a set of $n$ elements (in our case, category members). $\mathrm{S} /$ he then generates a set of $m$ constructs (or semantic scales) on which the elements can be discriminated. In order to elicit constructs, the subject can be given $m$ triads of elements, drawn randomly from her/his own set of elements; the subject is asked to define some characteristic in which two of the elements are similar to each other but different from the third. This results in $m$ unique bipolar scales, since subjects are discouraged from repeating scales. In the final phase, the subject ranks or rates (as in our study) all $\mathrm{n}$ elements with respect to all $\mathrm{m}$ scales. The resulting $\mathrm{n}$ by $\mathrm{m}$ matrix is then subjected to a principal-components factor analysis (Slater, 1977), which produces a set of orthogonal factors in decreasing order of the proportion of variability for which they account. The analysis provides a complete set of factor loadings for both elements and constructs, and plots a multidimensional factor space within which interelement "distances" are computed. Interpretation of the factors is usually attempted by an examination of both the items with highest loadings on the factor in question and by examining the scales with highest loadings on the factor. The scales can be directly used in attempts at labeling the dimension. It is worth noting that attempts at inter. preting and labeling the dimensions obtained in multidimensional scaling studies of semantic memory have so far relied on eyeball inspection of the configurations of the items scaled and on intuitions about what the dimensions responsible for the configurations might be. More satisfactory and objective dimension labeling techniques, termed "property fitting," exist and have been utilized in other applications of multidimensional scaling (Kruskal \& Wish, 1978), but the subjects are required to make additional lengthy unidimensional scale judgments after completing the similarity judgments required by multidimensional scaling.

In Experiment 1 the repertory grid technique was used to investigate the semantic category "bird names." This category was chosen because it is large and because it has been extensively investigated in semantic memory using a variety of techniques. Investigators using multidimensional scaling (Caramazza, Hersh, \& Torgerson, 1976; Henley, 1969; Rips, Shoben, \& Smith, 1973) have on the whole concluded that two semantic dimensions suffice as the basis of similarity judgments for birds and for mammals. These two dimensions have been labeled "size" and "ferocity/predatoriness." If individual differences in semantic structure between subjects are unimportant, then these two dimensions should emerge as the two most important components from the principal-components analysis of the repertory grid data for most, if not all, subjects.

\section{EXPERIMENT 1}

In Experiment 1 each subject was asked to think of 20 bird names, writing them down in the order in which they came to mind. For each subject, 20 randomly selected triads of the bird names s/he produced were then presented, and the subject was required to list a set of 20 bipolar scales in response to the triads. The bird names were then rated along the 20 scales.

\section{Method}

Subjects. Sixteen male and female undergraduates or recent graduates of the City of London Polytechnic were tested and paid for participation in the 45 -min session. 
Task and Procedure. The subjects were informed that they might participate in several language experiments and were tested individually. Each subject was initially asked to write down 20 bird names. Then he or she was presented with 20 different triads of these names, one triad at a time. Triads were selected randomly from the set of 20 names, with the constraints that each bird name appeared approximately equally often and that triad combinations of the same names could not recur. Order of triad presentation was randomized.

On presentation of a triad of bird names, the subject was asked to describe a way in which two of the birds were alike and the third different from them. The resulting descriptions, termed "scales," were recorded. In this way, 20 bipolar scales were elicited. A subject who gave a description given earlier by her/him was asked to think of another way in which two birds differed from the third. The subject was then asked to rate each bird name on each scale, rating the 20 bird names on one scale at a time. A 6-point rating scale having the values $+3,+2$, $+1,-1,-2,-3$ was used and indicated the extent to which each bird name possessed the characteristic under consideration.

\section{Results}

The bird names. Although the 16 subjects emitted about 90 bird names, certain bird names were commonly produced. The most frequent were (in order of frequency): robin, eagle, duck, sparrow, pigeon, goose, blackbird, thrush, wren, and owl. All of these were listed by at least $50 \%$ of the subjects.

The scales. The number of scales described by the subjects was large. These can be broadly classified as pertaining to physical appearance, habitat, country of origin, and behavior. Characteristics such as webbed feet, degree of wing development, shape and length of the legs, the beak, the wings or the body, and size were included. Color and attractiveness were also mentioned. Constructs based on habitat were common, and included distinctions between water (or sea) and land birds, climate of the habitat, and distinctions between forest, garden, town, country, and farm habitats. British and foreign birds were distinguished by some scales, and exotic or unusual birds were contrasted with common birds by other scales. Many scales concerned behavior characteristics that inciuded the ability to fly, style of flying, method of nest building, swimming, running, and singing. Dietary characteristics were the basis of some scales, with fish eaters being contrasted with grain eaters and others. Wild birds were contrasted with domestic or caged birds, and edibility was a quality noted by some subjects.

Principal components analysis. Each subject's data matrix was analyzed by a technique known as principalcomponents analysis, using the program INGRID 72, which has been written specifically to apply the technique to repertory grids (see Slater, 1977). This analysis includes a test derived by Slater from Bartlett (1950) which assesses the significance of the components obtained. The Bartlett test assumes that most of the variation occurs in a few dimensions and that the remainder is dispersed randomly in the component space. Thus the dimensions having greatest variance are examined one by one, and a value of chi square can be used to assess whether the residual variation is randomly distributed. However, caution must be exercised in assessing the Bartlett test results, because paradoxical findings are sometimes obtained (see Slater, 1977). The Bartlett test indicated the presence of several significant components for all subjects, ranging from $2 \mathrm{com}$ ponents significant to 15 components significant. However, since the bulk of the variance was contained in the first three components, attention was primarily directed at them.

An attempt was made to interpret and label the first three components for each subject.Principal-components analysis provides a loading for both the instances and the scales and the instances with highest loadings on a given component, and used this information to label the components. ${ }^{1}$ The labels presented in Table 1 were the result of a consensus among the judges. For example, the first component for Subject 13 accounted for $41 \%$ of the variance for that subject, and the following scales had the heaviest loadings on Component 1: eats fish/

Table 1

The First Three Components and Percentage of Variance (PV) Contributed by Each One

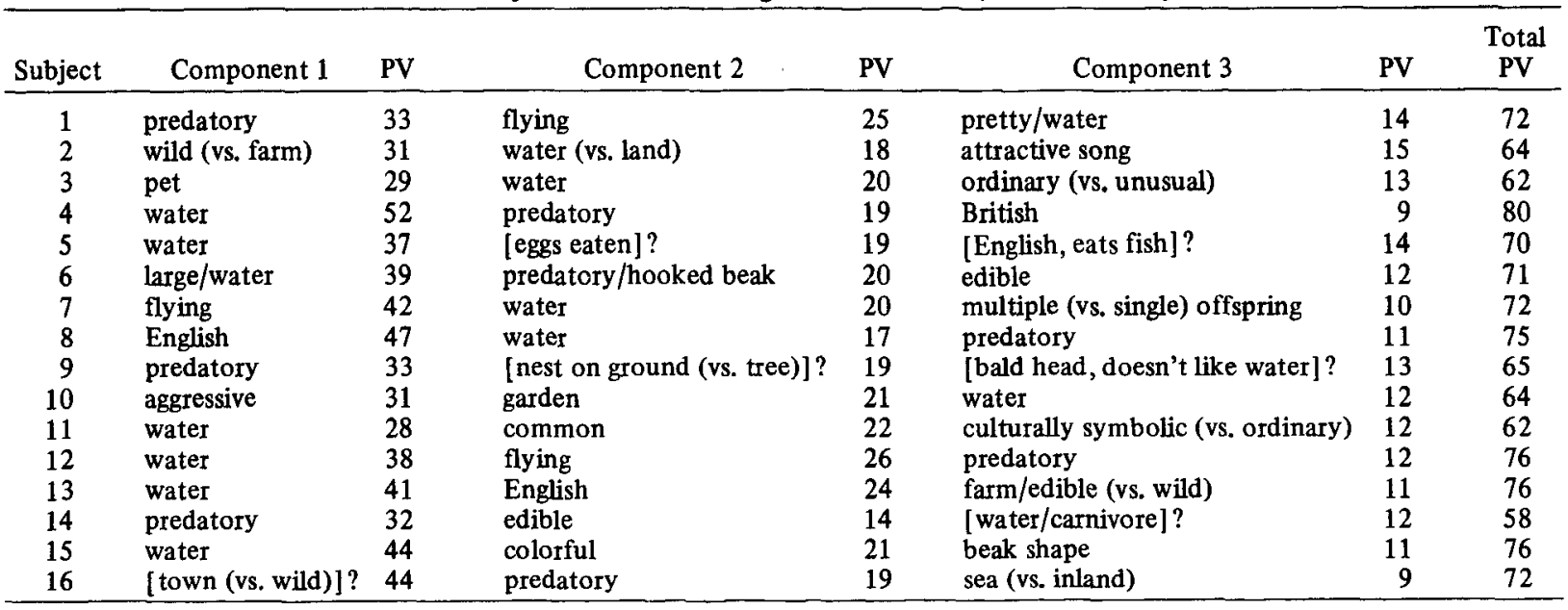


eats worms, small/big, sea bird/land bird, nests in reeds/ nests in trees, has webbed feet/does not have webbed feet, runs/flies; for that subject the birds with the highest positive loading on Component 1 were penguin, duck, puffin, and swan, whereas cuckoo and robin had the highest negative loadings on Component 1 . The first component was therefore labeled a water-bird vs. land-bird dimension. A few components, namely those of Subjects 5, 9, and 14, were difficult to interpret and label, and this is indicated by brackets and question marks in Table 1.

Inspection of Table 1 shows that the first three components accounted for a substantial proportion of the variance, over $70 \%$ for 10 of the subjects. It is also evident that there was considerable variation in the components produced by different subjects. The most common component, produced by all but one subject, was a water-bird vs. land-bird dimension. The second most frequent component seemed to be based on predatoriness/aggression vs. lack of it; this component emerged from nine subjects. Four subjects produced components distinguishing between wild and farm/ domestic birds (or pets), four subjects had a component distinguishing between British and foreign birds, and four had a component characterizing the edibility of the birds.

Interbird distances and emission order. Clustering based on semantic similarity has regularly been observed in free emission of instances of verbal categories (Bousfield \& Sedgwick, 1944; Henley, 1969; Mandler, 1975). Henley (1969) found that animals shown to be similar by multidimensional scaling tended to occur close together in the free emission of animal names. Our principal-components analysis provided interbird distances. If these genuinely reflected similarity in meaning among bird names, then it would be predicted that bird name pairs with short distances between them should have occurred nearer to one another in emission order than bird names with greater distances between them.

The interbird distances provided by the principalcomponents analysis were used to select the 10 closest pairs of bird names and the 10 most distant pairs of bird names, individually for each subject. The difference in rank order of emission was calculated for each of the bird name pairs. If for a given pair, one bird name was emitted third and the other fifth in the list of 20 , then the emission distance between them is two. Mean emission distances for the 10 closest and 10 most distant pairs of bird names were calculated for each subject. Averaging over subjects, the mean emission distance for close pairs was 5.09 , and for distant pairs it was 7.67; the difference between the distances was significant $[\mathrm{t}(15)=4.03, \mathrm{p}<.01]$. Thus the proximity of the bird names in the emission task reflected their proximity in the semantic space derived from the repertory grid technique.

\section{Discussion}

The results showed that although most subjects emitted the bird names most commonly found in the category norms, the set of 20 bird names listed differed greatly from subject to subject. Many bird names were mentioned by only one or two subjects. Similarly, the descriptive scales elicited from the subjects and the components obtained from the principal-components analysis differed markedly across subjects. In previous multidimensional scaling studies, all subjects were presented with a common set of bird names chosen by the experimenter, and statistical analyses were based on group rather than individual data. In these studies, scaling solutions based on only two dimensions (interpreted as size and ferocity) were accepted as the best representation of the meaning of bird names (Caramazza et al., 1976; Rips et al., 1973).

In the experiment reported here, size was commonly produced by subjects as a scale. Size was a scale that contributed to one of the first three components for 11 of the 16 subjects. For two subjects it contributed to two of the first three components. For five subjects size contributed to the water component, for two it contributed to the predatory component, for two to the English/foreign component, and to other components for the remainder. In these cases size had on average the fourth highest loading on the components concerned. An examination of the contribution of size to components beyond the first three was carried out. This showed that size was occasionally associated with additional components. For example, for Subject 2, size had a moderate loading on Component 2 , which was the land-water dimension, and size was also associated with "rare/not rare," which made up Component 8 for that subject. Since Component 8 contributed only $2.5 \%$ of the total variance, it cannot have been very important. Size did not clearly dominate any component, even when the constituents of components other than the first three were inspected. Although the predatoriness/ ferocity dimension was quite common, it also was not universal, and emerged as one of the first three components in just over half of the subjects. A land-water bird dimension (which has not previously been reported) was produced by 15 of the 16 subjects. Although this dimension was the most prevalent, it was not necessarily the first component for all. It was the first component for seven subjects, second for four, and third for four. Inspection of the bird names emitted showed that most subjects listed four to six water birds: two or three common water birds such as duck, goose, sea gull, or swan and several less common water birds. In the multidimensional scaling studies referred to earlier, only one or two water birds were included in the sets scaled by subjects. This underrepresentation may account for the fact that the land-water dimension did not emerge in these previous studies. However, it should be pointed out that the land-water dimension emerged in Experi- 
ment 1 even in a subject who emitted only two water birds. Furthermore, there appeared to be no systematic relationship between the number of water birds listed by subjects and the importance of the land/waterbird dimension. It appears, then, that our idiographic approach revealed a somewhat different and more varied structure underlying semantic memory for bird names than did group-based multidimensional scaling studies.

The fact that birds with shorter semantic distances between them were closer together in emission order supports the validity of the structure uncovered by the repertory grid technique. However, the validity of the structure obtained requires further demonstration. For example, it should be possible to predict how people process information about bird names in other experimental situations on the basis of repertory grid analysis. Experiments 2 and 3 were designed to investigate whether the structure revealed by the principalcomponents analysis could be used to predict performance in RT tasks.

\section{EXPERIMENT 2}

The subjects who participated in Experiment 1 were subsequently required to judge the instances they had previously listed with respect to the scales they had previously generated. Each subject was presented with the descriptive scales $s /$ he had described and judged the previously listed 20 bird names with respect to the poles of each scale. For example, a subject had to decide as quickly as possible whether robin (a bird s/he had previously listed) had fully developed wings or undeveloped wings (a scale s/he had previously given). The time taken to make each decision was recorded. It was predicted that there would be an inverted U-shaped function relating choice RT for an instance to location of that instance on the particular bipolar scale as determined in Experiment 1. This hypothesis derives from considerations of the fact that judgments on internally represented dimensions tend to have psychophysical properties. For example, Moyer (1973) has shown that RTs to judge the differences in size between animals are inversely related to the magnitude of the size differences. Similarly, when subjects are given information that permits them to rank objects along a transitive scale, they are able to make comparative judgments more quickly for remote objects than for adjacent ones (see Potts, 1978, for a review). In our experiment, subjects classified objects as lying toward one pole or the other of a bipolar scale. It seems reasonable to suppose that the nearer an object is to either pole as opposed to the center, the more "discriminable" it will be with respect to that scale and the more likely it will be associated with a quick decision.

\section{Method}

Subjects. The 16 subjects from Experiment 1 returned approximately 4 weeks later to participate in the second experiment.
Apparatus and Stimuli. The bird names elicited in Experiment 1 were typed on cards for presentation on a Cambridge two-field tachistoscope equipped with two response keys.

Procedure. The subjects were asked to make speeded judgments about the bird names they had listed in Experiment 1. Each bird name was tested on each of the 20 scales elicited from that subject in Experiment 1. Thus, a subject had to judge whether each bird "flies" or "does not fly," if that was a scale s/he had previously described. The response keys were labeled with the poles of each scale for the block of 20 trials associated with that scale. The 20 scales were presented in different random orders to each subject, and the order of presentation of bird names was also randomized separately for each scale.

\section{Results and Discussion}

For each subject, the mean RT for all items rated with each of the 6 points of the scale was calculated. The mean of all subjects combined for these categories is displayed graphically in Figure 1 and follows the general inverted-U shape predicted. Statistical confirmation was obtained by means of a parametric trend analysis that computed the six mean scores of the 16 subjects in a combined group analysis. The linear component was nonsignificant and accounted for only $2 \%$ of the treatment sum of squares. As expected, the quadratic component was highly significant $[\mathrm{F}(11,75)=$ $36.3, p<.001]$, and this accounted for $78 \%$ of the treatment sum of squares. Thus, the prediction of shorter latencies on more extreme ratings was well supported.

The principal-components analysis produces a multidimensional spatial representation of the scaled items, that is, the bird names in this experiment. If this spatial representation has psychological reality-that is, if it reflects the relative locations of the stored representations of bird names in semantic memory-then one should be able to make predictions about the way in which subjects perform other linguistic tasks involving bird names. Here we make the following assumption about the relationship between structure and processing

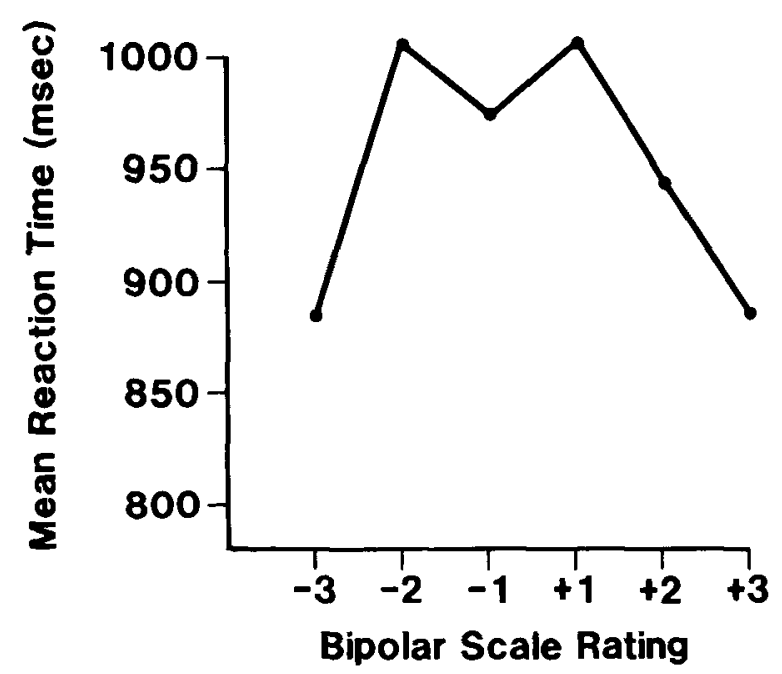

Figure 1. Mean reaction times as a function of bipolar scale ratings $(\mathrm{N}=16)$. 
in tasks depending on semantic memory. If a subject has to access semantic memory to retrieve information about a category member in order to perform a linguistic judgment such as categorization, then it will take less time to retrieve subsequently another instance that is close in the semantic space to the first member accessed than to retrieve an instance that has a more remote location. Experiment 3 was designed to test whether the structure yielded by the repertory grid technique would lead to successful predictions about processing in a speeded judgment task.

\section{EXPERIMENT 3}

The principal-components analysis of the data of Experiment 1 provided interbird name distances. Experiment 3 aimed to investigate whether these distance measures could be used to predict categorization RT. Semantic facilitation effects have been reported by Meyer and Schvaneveldt (1971) and Neely (1977) in a lexical decision task. In this task the subject is required to judge whether or not a letter string is a word. When two consecutive strings are both words, RT to the second word is faster if that word is semantically related to the preceding word than if the two words are unrelated. For example, in an experiment using bird names as the lexical decision items, subjects were faster at judging that "robin" is a word when it was preceded by the word "BIRD" than when it was preceded by a word unrelated in meaning, such as "BODY" or "BUILDING" (Neely, 1977). Further research by Fischler (1977) has shown that semantic relatedness independent of word association will produce this facilitation effect. Rosch (1975) also showed facilitation of category judg. ments when primed by an appropriate name. It should be pointed out that these experiments did not examine within-category priming effects.

In Experiment 3 subjects were given a categorization RT task. They were presented with pairs of words in rapid succession and had to indicate whether or not each word was a bird name. The RTs of interest were those to bird names preceded by another bird name. The interbird distances derived from the principal-components analysis in Experiment 1 were used to select pairs close or distant in meaning. If the distances genuinely reflect semantic relationships in the internal lexicon for bird names, then there should be RT facilitation when a subject has just categorized a bird name that is semantically close to the current bird name, as compared with when the two bird names are semantically distant. Therefore, in Experiment 3 the previously tested subjects had to perform a categorization RT task responding to pairs of words presented in rapid succession. Trials on an unrelated category (sports) were included, both to serve as practice trials and to separate the two blocks of "bird" trials, since bird names in the second position in a trial were repeated in Block 2 . Thus, bird $X$ occurred once in Block 1 trials, in which it was preceded by bird $Y$, and once in Block 2 trials, in which it was preceded by bird Z. "Sports" trials separated the blocks and served to minimize facilitation effects produced by repetition of bird names in Block 2.

\section{Method}

Subjects. Ten of the subjects who participated in Experiment 1 and 2 were available several months later and were tested.

Stimulus materials. For each subject, ${ }^{2} 10$ pairs of bird names were selected. Five bird names were used as the second member of the pairs. Each was preceded by a bird name with a short interinstance distance and by a bird name with a long interinstance distance, these distances being determined from the principal-components analysis performed for Experiment 1 . Other bird names were paired with unrelated concrete nouns of similar word frequency. For the filler and practice trials, instances of sports were chosen from the Battig and Montague (1969) category norms. Unrelated negative instances, concrete nouns of similar frequency, were also chosen for inclusion in the "sports" trial blocks. For "bird" trials the negative instances similarly consisted of unrelated nouns which were unrelated to the "bird" category. Each subject responded to 50 pairs of words. These included a block of 10 practice trials on which the subject had to categorize words as sports or nonsports. A trial consisted of a pair of words that occurred in succession, each of which required a yes/no response. Ten trials on the bird category followed; then there were 20 filler trials on sports; and, finally, there were another 10 trials on birds. Half the bird trials contained pairs of positive instances and half the trials contained a positive and a negative instance. The words were typed in capitals on tachistoscope cards.

Apparatus and Procedure. The stimuli were presented on a three-field Electronic Developments tachistoscope. Subjects responded "yes" or "no" by pressing one of two keys, using their preferred hand. Assignment of response to key was determined randomly for each subject. The subjects were instructed to classify all words presented with respect to a designated category indicated by the experimenter at the beginning of a block of trials. A trial consisted of a 500-msec exposure to a fixation point, followed by the first word presented for $2 \mathrm{sec}$; then the fixation point followed for $500 \mathrm{msec}$, and finally the second word was presented for $2 \mathrm{sec}$. The subject had to respond to each word as quickly as possible, and the RT was recorded. Trial order was randomized, except that for the bird name trials approximately equal numbers of "close" pairs and "distant" pairs occurred in each block.

\section{Results}

The data of interest were the categorization times for the second word when both words in a trial had been bird names. For each subject there were 10 trials on which bird-bird pairs had been presented. The five bird names, which were the second words used, were preceded on half the trials by a "close" bird and on half the trials by a "distant" bird, these distances having been obtained from the principal-components analysis performed in Experiment 1. The mean RT for bird names following a "distant" bird name was $599 \mathrm{msec}$; the mean RT for the same bird names when they occurred after "close" bird names was $568 \mathrm{msec}$. The difference between the means was significant $[\mathrm{t}(9)=2.55, \mathrm{p}<.05$, one-tailed].

\section{Discussion}

A semantic facilitation effect resembling that obtained 
by Meyer and Schvaneveldt (1971) and Neely (1977) in lexical decisions was observed in a task involving categorization. It is noteworthy that in the lexical decision literature semantic facilitation is computed by comparing RTs for pairs of words that are semantically related with RTs for pairs that are unrelated. In Experiment 3 the comparison involved sets of words that were all related. That is, the categorization of a bird name was facilitated by the prior presentation of a bird name that was close in meaning to it compared with the prior presentation of a bird name that was quite distance in meaning.

These results should perhaps be contrasted with those of Neely (1977) and Rosch (1975). Rosch (1975) used category names as primes for pairs of words, and her subjects had to judge whether or not the pair belonged to the same semantic category. When the pair members were physically identical and were instances of the category name used as prime, there was (in most of her experiments) a facilitation effect which was enhanced for highly typical instances. When the pair contained nonidentical positive instances of the category prime, typicality did not influence categorization time. This result is less surprising if considered with reference to our results. Experiment 3 suggests that categorization time for a pair of instances will depend on the similarity (or proximity) between them. Thus, "chicken" and "turkey" may be atypical birds, but their categorization as birds may be speeded by the fact that they are semantically close to each other and retrieval of one will facilitate retrieval of the other. However, recent work by McCloskey (1980) suggests that "typicality" effects may be confounded with familiarity and that estimates of semantic distance between category name and category instances are likewise confounded with familiarity. Furthermore, as Tversky (1977) has argued, the relationship between instances and categories is not symmetrical and hence instance-category relationships, being qualitatively different from instance-instance relationships, may not affect speeded classifications in the same way. Finally, it should be added that, as Becker (1980) has convincingly demonstrated, the effects of primes depend crucially on the characteristics of the entire stimulus list presented to the subjects. Becker showed that facilitation effects dominate when primes are strongly related to the primed words and semantically unrelated to the words used as baseline controls. Interference dominance results when a wide range of similarity characterizes the relationship between prime and target words. McCloskey and Glucksberg (1979) also found list characteristics to be an important determinant of sentence verification. Although Experiment 3 was not designed with these considerations in mind, its conditions correspond to those yielding facilitation dominance.

The fact that presentation of a bird name can facilitate the categorization of a subsequent bird name close to it in meaning can be readily explained both by the network model of Collins and Loftus (1975) and by the Smith et al. (1974) featural model. Collins and Loftus assert that when a word is presented activation spreads through the paths of the network from the node representing that word. In Experiment 3 categorization of the first of a pair of bird names would result in a spread of activation from the node representing that bird to other nearby nodes and links in the network. The node for a bird name close in meaning would thus have many of its links activated; as a result, the bird name would be identified and categorized more rapidly. A feature comparison model would predict that two highly similar instances could be categorized as belonging to the same category after Stage 1 processing and would not require Stage 2 activation.

However, the decision that both are, or are not, members of a specified category could involve either Stage 1 or Stage 2 activation, depending on the relationship of the pair to the category name. A within-category priming effect has not been explicitly predicted by the featural model of Smith et al. (1974), which has been elaborated more recently by Shoben (1976) to account for categorization of unrelated pairs of words. Thus far this model has been restricted to dealing with instance to category relationships.

\section{GENERAL DISCUSSION}

The repertory grid technique, employed in this study, has proved useful for investigating the semantic memory of individual subjects. The validity of the principalcomponents analysis has been demonstrated in several ways. In Experiment 1, the interitem difference in the semantic space inferred from the analysis was shown to predict the clustering of item emission. In Experiments 2 and 3, features of the subjects' repertory grid responses and the associated semantic space were shown to predict RT in cognitive processing tasks, including categorization and other semantic decisions.

There are a number of differences between our work and orthodox multidimensional scaling studies. In the latter, all subjects are presented with a small common set of bird names whose similarity has to be compared. Rips et al. (1973) presented 12 instances which were the most common bird names produced by a large local sample of students in a free emission task. Caramazza et al. (1976) also chose frequent instances but included bird names that might be expected to reflect the extremes of the semantic domain. In Experiment 1 the subjects listed their own instances. Many of these bird names are bird names commonly given in the BattigMontague (1969) norms. However, each subject listed, in addition, a number of unusual instances. Some of these were water birds. Thus, most subjects listed the common water birds, duck and goose, but added less common ones, such as pelican, penguin, kingfisher, and so on. 
Brown (1978) has shown that there are systematic differences in certain of the category norms obtained from British and American students and that the category of bird names is one such case. Bluebird and cardinal are familiar to American students but not to British students. Conversely, blackbird is more familiar to British subjects. However, these are not water birds, and are unlikely to provide an obvious explanation for the emergence of the land-water dimension in Experiment 1. Furthermore, since a substantial number of birds listed in Experiment 1 were the birds commonly found in American category norms, the differences in the dimensions emerging from the principal-components analysis and those from multidimensional scaling are unlikely to be caused solely by differences in the bird instances used in these studies. Instead, it appears that the idiographic method used here suggests that semantic memory has a richer and more idiosyncratic structure than that indicated by the multidimensional scaling studies hitherto reported. Thus, the repertory grid technique appears to be a promising technique for the investigation of the structure underlying semantic categories; further research comparing it with multidimensional scaling seems warranted. It should perhaps be mentioned that modifications of the original individual grid have been developed (Slater, 1976, 1977) with suitable computer programs. It is possible to derive consensus grids from groups of subjects when the subjects are scaling a common set of items (program PREFAN), or when they are scaling different items using a common experimenter-provided set of bipolar scales (program COIN), or, finally, when both items and scales are supplied by the experimenter (program SERIES). Clearly, comparisons of the results of such differing methods of scaling would be informative. It should be added that individual differences can be represented and assessed by three-way multidimensional scaling methods such as INDSCAL (Carroll \& Chang, 1970). INDSCAL assumes that subjects share a common set of dimensions but that they may weight the dimensions differentially. Rips et al. (1973) used INDSCAL but did not give serious consideration to the possibility that individual differences might be important. Systematic comparisons between the results obtained from these techniques should more clearly establish the importance and nature of individual differences in the structure of semantic memory. Finally, it is suggested that systematic comparisons could be made between subjects known to differ in educational background relevant to the semantic category under investigation.

\section{REFERENCES}

Adams-Webber, J. R. Personal construct theory: Concepts and application. New York: Wiley, 1979.

BartLetT, M. S. Tests of significance in factor analysis. British Journal of Statistical Psychology, 1950, 3, 77-85.

Battig, W. F., \& Montaque, W. E. Category norms for verbal items in 56 categories: A replication and extension of the
Connecticut Category Norms. Journal of Experimental Psychology Monograph, 1969, 80(3, Part 2).

BEскEn, C. A. Semantic context effects in visual word recognition: An analysis of semantic strategies. Memory \& Cognition, 1980, 8, 493-512.

Bousfield, W. A., \& Sedgwick, C. H. W. An analysis of restricted associative responses. Journal of General Psychology, 1944, 30, 149-165.

Brown, W. P. A cross-national comparison of English-language category norms. Language and Speech, 1978, 21, 50-68.

Caramazza, A., Herbe, H., \& Toraerson, W. S. Subjective structures and operations in semantic memory. Journal of Verbal Learning and Verbal Behavior, 1976, 15, 103-117.

Carroll, J. D., \& Chang, J. J. An analysis of individual differences in multidimensional scaling via an $\mathbf{N}$-way generalization of "Eckart-Young" decomposition. Psychometrika, 1970, 35, 283-319.

Collins, A. M., \& Lortus, E. F. A spreading activation theory of semantic processing. Psychological Review, 1975, 82, 407-428.

Collins, A. M., \& Quillian, M. R. Retrieval time from semantic memory. Journal of Verbal Learning and Verbal Behavior, $1969,8,240-247$.

Collins, A. M., \& Quillian, M. R. Does category size affect categorization time? Journal of Verbal Learning and Verbal Behavior, 1970, 9, 432-438.

Conrad, C. Cognitive economy in semantic memory. Journal of Experimental Psychology, 1972, 92, 149-154.

Cramer, P. Word association. New York: Academic Press, 1968.

Fischler, I. Semantic facilitation without association in a lexical decision task. Memory \& Cognition, 1977, 5, 335-339.

HENLEY, N. M. A psychological study of the semantics of animal terms. Journal of Verbal Learning and Verbal Behavior, 1969, 8, 176-184.

KeLly, G. A. The psychology of personal constructs. New York: Norton, 1955.

Kruskal, J. B., \& WISH, M. Multidimensional scaling. Beverly Hills: Sage, 1978.

LoFTus, E. F. Category dominance, instance dominance, and categorization time. Journal of Experimental Psychology, 1973, 97, 70-74.

LorTus, E. F. Spreading activation within semantic categories: Comments on Rosch's "Cognitive representations of semantic categories." Journal of Experimental Psychology: General, 1975, 104, 234-240.

Mandle r, G. Memory storage and retrieval: Some limits on the reach of attention and consciousness. In P. M. A. Rabbitt \& S. Dornic (Eds.), Attention and performance $V$. London: Academic Press, 1975.

MCCloskey, M. The stimulus familiarity problem in semantic memory research. Journal of Verbal Learning and Verbal Behavior, 1980, 19, 485-502.

McCloskey, M., \& Glucksberg, S. Decision processes in verifying category membership statements: Implications for models of semantic memory. Cognitive Psychology, 1979, 11, 1-37.

Meyer, D. E., \& Schvaneveldt, R. W. Facilitation in recognizing pairs of words: Evidence of a dependence between retrieval operations. Journal of Experimental Psychology, 1971, 90, 227-234.

MOYER, R. S. Comparing objects in memory: Evidence suggesting an internal psychophysics. Perception \& Psychophysics, 1973, $13,180-184$.

NeEly, J. H. Semantic priming and retrieval from lexical memory: Roles of inhibitionless spreading activation and limited-capacity attention. Journal of Experimental Psychology: General, 1977, 106, 226-254.

Postman, L., \& KePPEL, F. Norms of word association. New York: Academic Press, 1970.

PotTs, G. R. The role of inference in memory for real and artificial information. In R. Revlin \& R. E. Mayer (Eds.), Human reasoning. New York: Wiley, 1978.

Rips, L. J., ShobeN, E. J., \& SMith, E. E. Semantic distance 
and the verification of semantic relations. Journal of Verbal Learning and Verbal Behavior, 1973, 12, 1-20.

Rosch, E. Cognitive representations of semantic categories. Journal of Experimental Psychology: General, 1975, 104, 192-233.

ShoBen, E. J. The verification of semantic relations in a samedifferent paradigm: An asymmetry in semantic memory. Journal of Verbal Learning and Verbal Behavior, 1976, 15, 365-379.

SLater, P. The measurement of intrapersonal space by grid technique (Vol. 1): Explorations of intrapersonal space. London: Wiley, 1976.

Slater, P. (Ed.). The measurement of intrapersonal space by grid technique (Vol. 2): Dimensions of intrapersonal space. London: Wiley, 1977.

Smith, E. E., Shoben, E. J., \& RIPs, L. J. Structure and process in semantic memory: A featural model for semantic decisions. Psychological Review, 1974, 81, 214-241.

Tversky, A. Features of similarity. Psychological Review, 1977, 84, 327-352.

WILkINs, A. J. Conjoint frequency, category size and categorization time. Journal of Verbal Learning and Verbal Behavior, $1971,10,382-385$.

\section{NOTES}

1. Forty of the 48 labels (or synonyms of them) in Table 1 were independently given by at least two of the three judges, who were the authors and Neil Hyland. In most cases the labels were the positive poles of one of the scales originally provided by the subject. Usually this was one of the three scales with highest loadings for the component under consideration. The remaining eight labels were given after a further joint inspection and discussion among the judges, and, as indicated, there was considerable doubt about the appropriate labels for some of the components for Subjects 5, 9, and 14.

2. For one subject the scaling solution yielded only six pairs, which fulfilled the requirements, and mean RTs were based only on responses to these pairs. The subject was, however, presented with additional pairs of bird names so that he responded to the same number and type of trials as did the remaining subjects.

(Received for publication June 10, 1980; revision accepted February 24, 1981.) 